\title{
Echocardiographic demonstration of free wall vegetative endocarditis complicated by a pulmonary embolism in a patient with ventricular septal defect
}

\author{
F ZIJLSTRA, P FIORETTI, J R T C ROELANDT \\ From the Department of Clinical Echocardiography, Thoraxcenter, Erasmus University and University \\ Hospital Dijkzigt, Rotterdam, The Netherlands
}

SUMMARY A defect in the muscular part of the interventricular septum in a 19 year old man was complicated by infective endocarditis caused by Staphylococcus aureus. The lesion was a large right ventricular free wall vegetation which embolised to the lungs. The vegetation was displayed by cross sectional echocardiography, which also confirmed the clinical diagnosis of ventricular septal defect. This case confirms the concept that the jet stream causes endocarditis at its point of impact. After six weeks' treatment with antibiotics the ventricular septal defect was repaired at operation.

Infective endocarditis is a rare complication of ventricular septal defects. Its incidence is estimated to be 2.2 per 1000 patient-years. ${ }^{12}$ Various sites may be involved-the tricuspid and pulmonary valves, the right side of the septal defect opening, less commonly the left side of the defect, and the site of impact of the jet stream on the right ventricular free wall (jet lesion). We report a patient with a large right ventricular free wall vegetation that was complicated by pulmonary embolism.

\section{Case report}

A 19 year old man who was known to have a cardiac murmur since birth, became ill and complained of a sore throat, malaise, and anorexia with a $5 \mathrm{~kg}$ weight loss. He had a temperature up to $40^{\circ} \mathrm{C}$. His general practitioner prescribed antibiotics. He remained febrile and some days later he was referred to our department by his community hospital. On physical examination his temperature was $38.7^{\circ} \mathrm{C}$, pulse rate $106 \mathrm{beats} / \mathrm{min}$, and blood pressure $120 / 70 \mathrm{~mm} \mathrm{Hg}$. A grade 4/6 pansystolic murmur was heard along the left sternal border. The liver and spleen were not palpable. Neurological examination and fundoscopy were normal and there were no other peripheral

Requests for reprints to Dr F Zijlstra, Thoraxcenter, University Hospital Dijkzigt, Rotterdam, PO Box 1738, 3000 DR Rotterdam, The Netherlands. signs indicative of endocarditis. Chest $x$ ray and electrocardiogram were normal. Two blood cultures grew penicillin resistant Staphylococcus aureus. Treatment with oxacillin and gentamicin was started, his clinical condition improved, and the fever subsided in a week.

Echocardiography clearly showed a defect in the muscular part of the interventricular septum (Fig. 1a and $b$ ) and a large vegetation on the right ventricular free wall (Fig. 1c). On two subsequent echocardiographic examinations one and two weeks later the appearance of the vegetation remained unchanged. Four days after the third echocardiogram the patient suddenly experienced pleuritic pain on the right side. Echocardiography was repeated and the vegetation was no longer present (Fig. 1d). A radioalbumin scan of the lungs (Fig. 2) showed a right basal perfusion defect which was not present on the lung scan made two weeks earlier. The patient, however, did not develop dyspnoea, cough, haemoptysis, fever, or other clinical signs of pulmonary embolism, and the chest $x$ ray remained normal.

After he had completed a six week antibiotic course he underwent surgical closure of the ventricular septal defect. The surgeon did not find any infective lesions near the ventricular septal defect and there were no vegetations on the right ventricular free wall. The pulmonary and tricuspid valves were normal. 

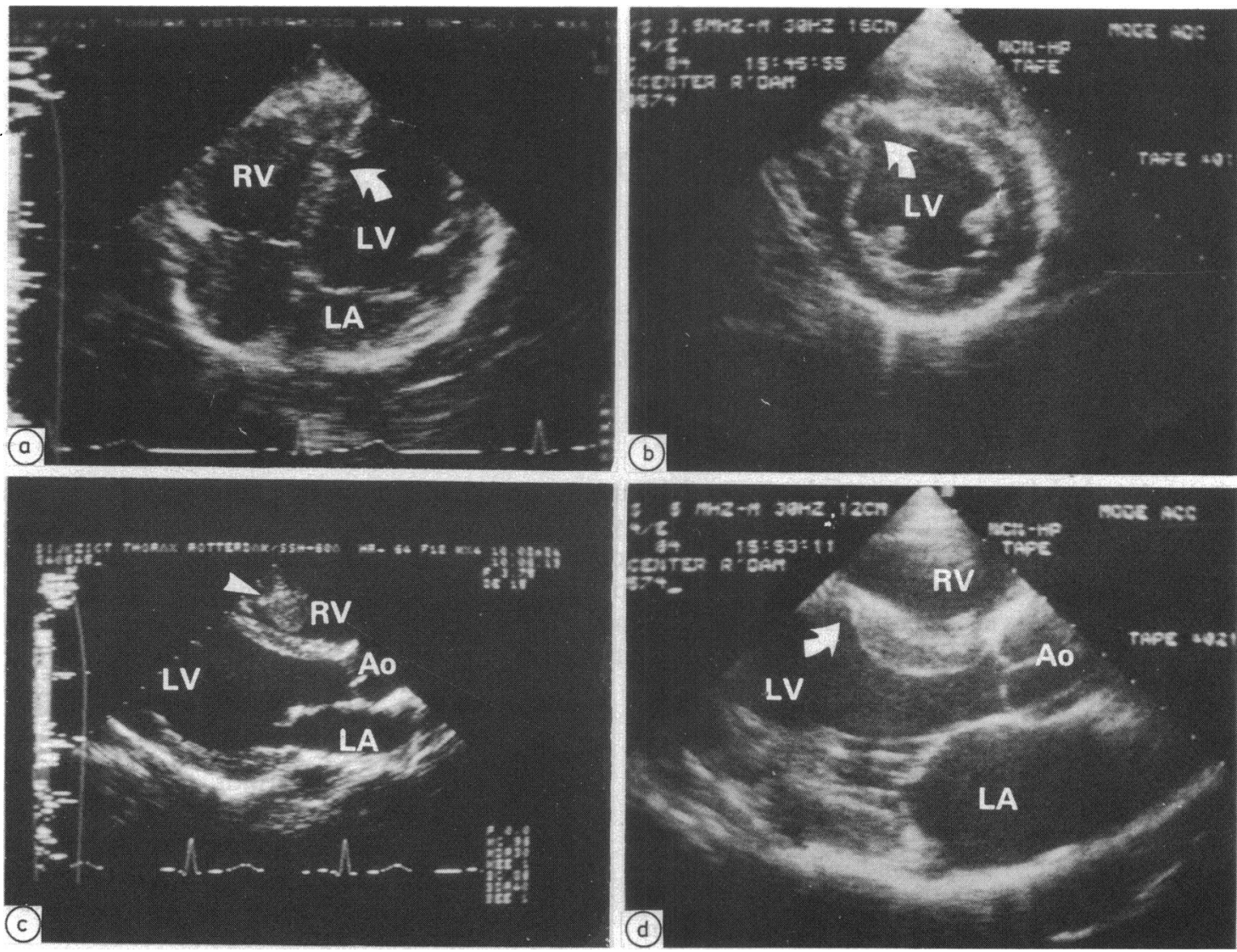

Fig. 1 Cross sectional echocardiograms in a patient with a ventricular septal defect and vegetation on the right ventricular free wall. The defect in the muscular part of the interventricular septum is seen in the apical four chamber view (a) (arrow), and in the parasternal short axis view (b) (arrow). In the parasternal long axis view (c) the arrow points to a large right ventricular free wall vegetation, which had disappeared three weeks later $(d) . R V$, right ventricle; LV, left ventricle; Ao, aorta; $L A$, left atrium.

\section{Discussion}

Infective endocarditis continues to be a serious risk in patients with congenital heart disease. Despite improved antibiotic treatment and prophylactic measures mortality is considerable. ${ }^{1-3}$ The advent of cross sectional echocardiography is a major advance. ${ }^{4-6}$ In our patient it confirmed the clinical diagnosis of a ventricular septal defect and showed the right ventricular vegetation. Apart from the ventricular septal defect no other lesions of the endocardium were found. We therefore must presume that the vegetation on the right ventricular free wall was the only abnormality. This case confirms the concept that the jet stream causes endocarditis at its point of impact. Because it was felt that there was a risk of recurrent endocarditis on the jet lesion, the patient underwent closure of the ventricular septal defect. Operation was performed on the basis of the cross sectional echocardiographic findings without

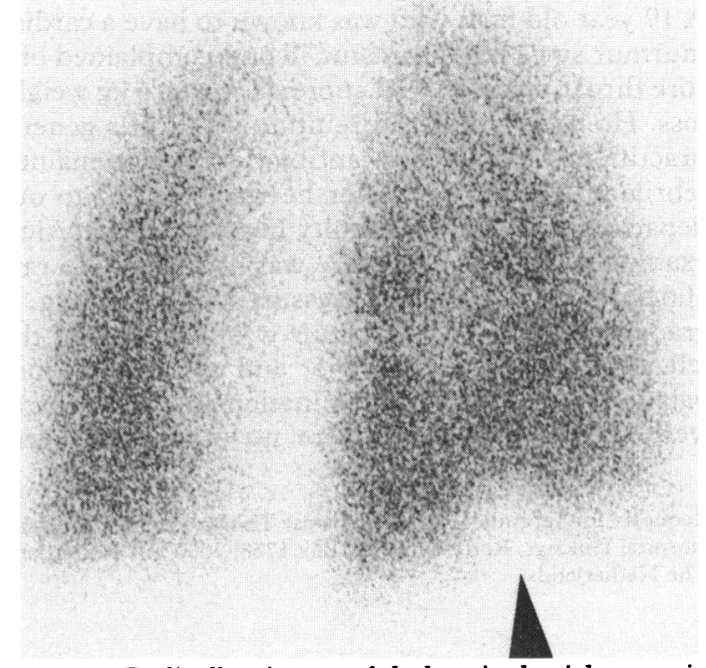

Fig. 2 Radioalbumin scan of the lung in the right posterior oblique view. The arrow points at a right basal perfusion defect. 
preoperative cardiac catheterisation. This case also illustrates that embolisation of large vegetations to the lungs can pass almost unnoticed.

\section{References}

1 Shah P, Singh WS, Rose V, Keith JD. Incidence of bacterial endocarditis in ventricular septal defects. Circulation 1966; 34: 127-31.

2 Corone P, Doyon F, Gaudeau S, et al. Natural history of ventricular septal defect: a study involving 790 cases. Circulation 1977; 55: 908-15.

3 Kramer HH, Bourgeois M, Liersch R, et al. Current clinical aspects of bacterial endocarditis in infancy, childhood and adolescence. Eur $\mathcal{F}$ Pediatr 1983; 140: 253-9.

4 Martin RP, Metlzer RS, Chia BL, et al. Clinical utility of two-dimensional echocardiography in infective endocarditis. Am f Cardiol 1980; 46: 379-85.

5 Webb Kavey R, Frank DM, Byrum CJ, Blackman MS, Sondheimer HM, Bove EL. Two-dimensional echocardiographic assessment of infective endocarditis in children. Am $\mathcal{F}$ Dis Child 1983; 137: 851-6.

6 Agathangelou NE, Dos Santos LA, Lewis BS. Realtime two-dimensional echocardiographic imaging of right-sided cardiac vegetations in ventricular septal defects. Am ₹ Cardiol 1983; 52: 420-1. 